\title{
A novel embryo culture media supplement that improves pregnancy rates in mice
}

\author{
A R Highet ${ }^{1}$, T Bianco-Miotto ${ }^{2}$, K G Pringle ${ }^{1,3}$, A Peura ${ }^{1}$, S Bent ${ }^{4,5}$, J Zhang ${ }^{1}$, M B Nottle ${ }^{1}$, \\ J G Thompson ${ }^{1,6}$ and C T Roberts ${ }^{1}$ \\ ${ }^{1}$ Adelaide Medical School, ${ }^{2}$ School of Agriculture, Food and Wine, Robinson Research Institute, The University of \\ Adelaide, Adelaide, South Australia, Australia, ${ }^{3}$ Priority Research Centre for Reproductive Science, School of \\ Biomedical Sciences and Pharmacy, University of Newcastle, Newcastle, New South Wales, Australia, \\ ${ }^{4}$ Bioinformatics Facility, Robinson Research Institute, The University of Adelaide, Adelaide, South Australia, Australia, \\ ${ }^{5}$ Institute for Molecular Bioscience, University of Queensland, St Lucia, Queensland, Australia and ${ }^{6}$ Australian \\ Research Council Centre for Excellence in Nanoscale Biophotonics, Adelaide, South Australia, Australia
}

Correspondence should be addressed to C T Roberts; Email: claire.roberts@adelaide.edu.au

\begin{abstract}
The preimplantation embryo in vivo is exposed to numerous growth factors in the female reproductive tract, which are not recapitulated in embryo culture media in vitro. The IGF2 and plasminogen activator systems facilitate blastocyst development. We hypothesized that the addition of IGF2 in combination with urokinase plasminogen activator (uPA) and plasminogen could improve rates of blastocyst hatching and implantation in mice. B6BcF1 and CBAB6F2 mouse embryos were divided into one of four supplemented culture media treatment groups: (1) control (media only); (2) $12.5 \mathrm{nM} \mathrm{IGF2;} \mathrm{(3)} 10 \mu \mathrm{g} / \mathrm{mL} \mathrm{uPA} \mathrm{and} 5 \mu \mathrm{g} / \mathrm{mL}$ plasminogen; or (4) a combination of IGF2, uPA and plasminogen treatments. Embryo development to blastocyst stage and hatching were assessed before transfer to pseudopregnant recipient females and implantation, pregnancy rates and postnatal growth were assessed. After $90.5 \mathrm{~h}$ of culture, IGF2 $+\mathrm{U}+\mathrm{P}$ treatment increased the percentage of B6BcF1 embryos that were hatching/hatched and percentage developing to blastocyst stage compared with controls $(P<0.02)$. Following B6BcF1 embryo transfer, IGF2 $+U+P$ treatment increased implantation sites at day 8 of pregnancy compared with controls $(P<0.05)$. Replication in the CBAB6F2 mouse strain showed significant improvements in pregnancy rates at days 8 and 18 but not in blastocyst development. No adverse effects were seen on gestational age, litter size or birthweight, or the reproductive capacity of offspring of IGF2 + U + P treated embryos. For embryos susceptible to detrimental effects of in vitro culture, IGF2, uPA and plasminogen supplementation of culture media can improve pregnancy success, but the effect of treatment is dependent on the mouse strain.

Reproduction (2017) 153 327-340
\end{abstract}

\section{Introduction}

It is recognized that the preimplantation embryo in vivo is exposed to numerous growth factors and expresses receptors for at least insulin-like growth factor (IGF) 1 and 2 (Lighten et al. 1997), leukaemia inhibitory factor (LIF) (Wanggren et al. 2007), granulocyte-macrophage colony-stimulating factor (GM-CSF) (Sjoblom et al. 2002), heparin-binding epidermal growth factor (EGF)-like growth factor (HB-EGF) (Chobotova et al. 2002) and EGF (Jiang et al. 2000). More than a dozen different growth factors have been identified in the female reproductive tract with concentrations peaking during the window for fertilization and preimplantation embryo growth (Richter 2008). Molecules that have been identified by previous studies that improve in vitro blastocyst development in animal models include IGF1, LIF, GM-CSF, macrophage colonystimulating factor (M-CSF), HB-EGF, EGF and fibronectin, platelet-activating factor and transforming growth factor alpha (TGF- $\alpha$ ) (Hegde \& Behr 2012). Some of these have translated to beneficial effects in human embryo studies, including LIF, IGF1, GM-CSF, HB-EGF, EGF and the addition of laminin or fibronectin (Hegde \& Behr 2012).

IGF2 is one growth factor, in particular, that has been added to embryo culture media with the aim of improving blastocyst development. IGF2 and its receptors (IGF1R, IGF2R and insulin receptor) are expressed by human oocytes and preimplantation embryos (Lighten et al. 1997). All preimplantation stages have detectable IGF2 expression, which likely acts in an autocrine manner to promote preimplantation development, and expression extends into the post-implantation period 
(Lighten et al. 1997). In mouse embryos Igf2 mRNA is first expressed at the 2-cell stage of development when the embryo genome is first turned on (Rappolee et al. 1992, Schultz et al. 1992, 1993) and IGF2 protein has been detected in all cells of the mouse blastocyst (Rappolee et al. 1992). Following in vitro fertilization of mouse embryos, expression of lgf 2 mRNA is delayed until after the 8-cell stage and the amount of IGF2 protein is reduced (Stojanov et al. 1999). Interestingly, mouse embryos cultured with antisense IGF2 oligonucleotides have delayed blastocyst formation, and 20\% fewer cells (Rappolee et al. 1992), while addition of IGF2 to mouse embryo culture media improves development to the blastocyst stage and increases the proportion of blastocysts hatching (Desai et al. 2000). Exogenous IGF2 also increases total blastocyst, inner cell mass and trophectoderm (TE) cell numbers and increases glucose uptake by the mouse blastocyst (Harvey \& Kaye 1992a, O'Neill 1997, Pantaleon et al. 2003). In studies of human blastocysts, increased glucose consumption at day 4 was associated with higher pregnancy rates (Gardner et al. 2011). IGF2 also appears to be important for implantation, as implantation failure induced by VEGF inhibition was associated with downregulation of IGF2 in trophoblasts (Ghosh et al. 2011).

Successful implantation of the embryo into the endometrium is a highly controlled process of tissue invasion and involves the local production and activation of extracellular matrix (ECM)-degrading proteinases by the trophectoderm. Potentially, a combination of both growth factors and ECM-degrading enzymes may be required to reverse the detrimental effects of in vitro culture on blastocyst development and embryo implantation. Urokinase plasminogen activator (UPA), uPA receptor (UPAR) and plasminogen are known to play important roles in cellular invasion. Binding of the inactive proenzyme, pro-uPA, to uPAR cleaves the protein to form active UPA. Cell-bound uPA can then cleave the inactive plasminogen to proteinase plasmin (Kjoller et al. 1997), which can then go on to activate matrix metalloproteinases (MMPs) and directly degrade certain ECM components and promote invasion. In vivo, expression of UPA and UPAR in the mouse embryo is increased upon blastocyst formation, just prior to implantation (Sappino et al. 1989, Harvey et al. 1995). uPA is mainly localized to the trophectoderm (Aflalo et al. 2005, 2007) and its activity is increased both in vivo and in vitro in rat blastocysts (Zhang et al. 1994, Aflalo et al. 2004). However, as for IGF2, in vitro culture reduces uPA protein expression and activity in rat embryos (Aflalo et al. 2004, 2005). uPA is also expressed in trophoblast outgrowths from blastocysts in vitro, and is expressed by the trophoblast giant cells and in the ectoplacental cone just after implantation (days 5.5 and 6.5) in the mouse (Sappino et al. 1989, Teesalu et al. 1996). uPA is important for blastocyst attachment and implantation, for example, $\mathrm{T}^{\mathrm{w} 73}$ mutant embryos which have reduced levels of plasminogen activators do not implant (Axelrod 1985) and inhibition of uPA has been shown to decrease the extent of trophoblast outgrowth and attachment in vitro (Kubo et al. 1981). In addition, plasmin and plasminogen are known to improve blastocyst development and hatching rates, and increase attachment and subsequent outgrowth (Menino \& O'Claray 1986, Menino et al. 1989). This may be due to the ability of plasmin to proteolytically degrade the zona pellucida, as seen in bovine embryos (Cannon \& Menino 1998).

Novel interactions between IGF2 and the uPA system have been identified and may be important for blastocyst implantation in vivo. IGF2R and UPAR are known to interact with each other, at sites different from those used for binding IGF2 or UPA, respectively, to form part of a large plasma membrane complex (Nykjaer et al. 1998, Godar et al. 1999, Kreiling et al. 2003, Olson et al. 2004). IGF2-induced cell migration is dependent on UPAR, UPA and plasmin activity in a rhabdomyosarcoma cell line (Gallicchio et al. 2003). In addition, IGF2R also binds to plasminogen and controls the conversion of plasminogen to plasmin (Godar et al. 1999, Olson et al. 2004). Therefore, it has been hypothesized that binding of IGF2 to the IGF2R may increase IGF2R/ UPAR interactions and/or increase uPA binding to UPAR, resulting in increased plasminogen conversion to plasmin at the cell surface to increase cell migration (Gallicchio et al. 2003). We hypothesized that this interaction might also facilitate blastocyst hatching and subsequent implantation and placentation. We aimed to determine whether IGF2, UPA and plasminogen, in combination, can ameliorate the detrimental effects of in vitro culture by improving blastocyst development and hatching, as well as enhancing subsequent implantation after embryo transfer in two murine models: one utilizing embryos with sensitivity to in vitro culture and benefiting from trophic support (C57BL/6 hybrid) and one in which we observed a more 'robust' growth response (CBAB6). The more robust growth response is defined as having increased ability to remain viable and effectively develop in the challenging in vitro culture environment.

\section{Materials and methods}

\section{Ethical approval}

Ethics approval for this study was obtained from the University of Adelaide's Animal Ethics Committee. All mice were obtained from the University of Adelaide Central Animal House and were housed in clean conventional conditions on a cycle of $12 \mathrm{~h}$ light, $12 \mathrm{~h}$ darkness and received food and water ad libitum.

\section{Embryo collection and culture}

We employed two different mouse strains to assess the effects of in vitro embryo treatment combinations on pregnancy 
rates: (1) $\mathrm{C} 57 \mathrm{BL} / 6$ females that were mated with BalbC males to produce B6BcF1 embryos (B6 embryos). Embryos of $\mathrm{C} 57 \mathrm{BL} / 6$ hybrid strains are sensitive to detrimental effects of in vitro culture in the absence of exogenous trophic ligands (Jin \& O'Neill 2014) and so were used as a preliminary study to investigate the effects of treatment on embryo development and early pregnancy (to pregnancy day 8 ) in a susceptible model. (2) CBAB6F1 females (CBA X C57BL/6) that were mated with males of the same strain to produce CBAB6F2 embryos. This strain displayed higher pregnancy rates than the B6 strain and were used as a confirmation cohort and to study the effects of embryo treatment on late pregnancy (to term) and postnatal effects in the offspring.

C57BL/6 and CBAB6F1 female mice (21-25 days old) were injected subcutaneously with $5 \mathrm{IU}$ equine chorionic gonadotrophin (eCG; Folligon, Intervet, Bendigo, VIC, Australia) followed by a second injection $48 \mathrm{~h}$ later of $5 \mathrm{IU}$ human chorionic gonadotrophin (hCG; Chorulon, Intervet). Immediately following the second injection, C57BL/6 females were placed with BalbC males, and CBAB6F1 females were placed with CBAB6F1 males, overnight for mating. Twenty-three hours post hCG, females were killed by cervical dislocation and 1 -cell embryos were collected from the oviducts in BlastAssist stage 1 media (MediCult A/s, Jyllinge, Denmark). Embryos were incubated with $1 \mathrm{mg} / \mathrm{mL}$ hyaluronidase (Sigma-Aldrich) to remove the cumulus cells and were then washed three times in media before being placed into culture. All embryos were cultured in groups of 10 in $50 \mu \mathrm{L}$ drops under oil at $37^{\circ} \mathrm{C}$ in humidified $6 \% \mathrm{CO}_{2}, 5 \% \mathrm{O}_{2}$ in nitrogen. Ten embryos per $50 \mu \mathrm{L}$ drop is within the published optimal mouse embryo density ranges summarized by Reed et al. (2011) and a media volume per embryo intended to dilute the paracrine effects of endogenous IGF2 and waste products secreted by companion embryos. Five per cent oxygen was used as mouse embryos cultured in $21 \%$ oxygen (ambient) conditions show reduced development to the hatching stage (Jin \& O'Neill 2014).

\section{Optimization of IGF-II concentration}

In preliminary experiments, embryos were cultured in either media alone or increasing concentrations of IGF-II $(0.5,1$, 12.5, 25 or $50 \mathrm{nM}$ ). IGF-II did not alter development of 2-cell embryos to the cleavage stage at any concentration. However, IGF-II, only at $12.5 \mathrm{nM}$, significantly increased the proportion of blastocysts hatching compared with untreated controls $(15.6 \% \pm 2.0$ vs $9.4 \% \pm 3.2, P<0.05, n=10$ replicates for each treatment).

Addition of $10 \mu \mathrm{g} / \mathrm{mL}$ uPA and $5 \mu \mathrm{g} / \mathrm{mL}$ plasminogen to culture media has been shown to increase the effects of IGF2 on promoting invasion in a human trophoblast cell line (Roberts et al. 2007, unpublished observations).

\section{Culture media and treatments}

The media used for embryo culture was EmbryoAssist (stage 1) and BlastAssist (stage 2) sequential media system (MediCult $\mathrm{A} / \mathrm{s}$, now ORIGI A/s Denmark). All embryos were cultured in EmbryoAssist media overnight for $20 \mathrm{~h}$ and assessed for development to the 2-cell stage.
The 2-cell embryos were pooled into a single dish and then randomly allocated into one of four treatment groups: (1) control, which were cultured in EmbryoAssist media alone; (2) IGF2, which were cultured in media containing 12.5 nM IGF2 (GroPep, Thebarton, SA, Australia); (3) U + P, which were cultured in media containing $10 \mu \mathrm{g} / \mathrm{mL}$ urokinase plasminogen activator (uPA; Sigma-Aldrich) and $5 \mu \mathrm{g} / \mathrm{mL}$ plasminogen (Sigma-Aldrich); or (4) IGF2 $+\mathrm{U}+\mathrm{P}$ treatments, which were cultured in media containing a combination of $12.5 \mathrm{nM}$ IGF2, $10 \mu \mathrm{g} / \mathrm{mL}$ urokinase plasminogen activator and $5 \mu \mathrm{g} / \mathrm{mL}$ plasminogen.

Embryos were washed and then cultured in this media for a further $23 \mathrm{~h}$ (Fig. 1). Cleavage stage embryos were then transferred to BlastAssist media with appropriate treatment for further $48 \mathrm{~h}$. All embryo culture dishes were equilibrated to appropriate temperature and gas mix for at least $4 \mathrm{~h}$ before culture.

\section{Blastocyst scoring}

B6 and CBAB6F2 embryo development was scored at days 2, 3 and 5, then assessed for hatching (clear herniation of, or extrusion through, the zona pellucida by the trophectoderm) after 90.5-91.5 h since initiation of in vitro culture (Fig. 1).

\section{Embryo transfers}

Immediately following blastocyst assessment, the embryos were transferred to pseudopregnant naturally mated recipient females. An additional cohort of CBAB6F2 embryos (control: $n=391$, IGF2: $n=392, \mathrm{U}+\mathrm{P}: n=304, \mathrm{IGF} 2+\mathrm{U}+\mathrm{P}: n=392$ ) was transferred after $72 \mathrm{~h}$ of culture to avoid transferring embryos that were hatching at the time of transfer. These were scored after $72 \mathrm{~h}$, immediately before transfer.

For B6 embryo transfer, naturally ovulating female C57BL/6 mice (8-10 weeks of age) were caged with vasectomized males. For CBAB6F2 embryo transfer, naturally ovulating female CBAB6F1 mice were caged with vasectomized males.

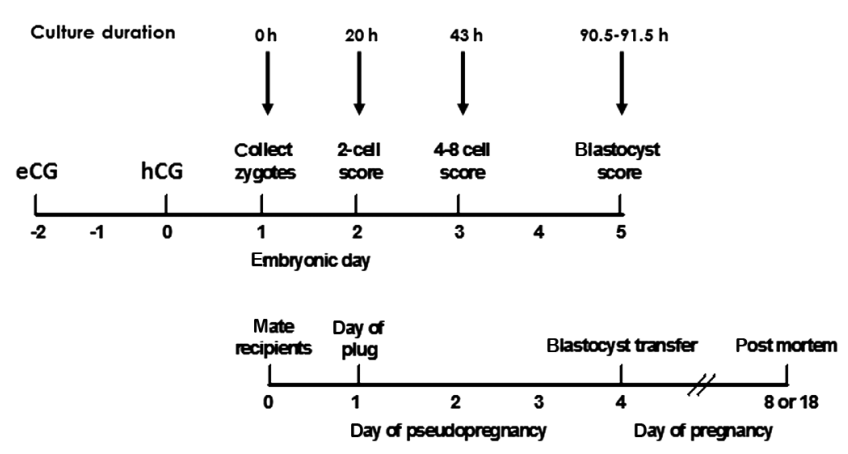

Figure 1 Timeline of embryo culture and blastocyst transfer. Embryos were cultured in vitro for a total of 90.5-91.5 h (top line). Immediately following blastocyst assessment, embryos were transferred to pseudopregnant naturally mated recipient females (bottom line). Additionally, a cohort of CBAB6F2 embryos was transferred after $72 \mathrm{~h}$ of culture because they were found to be developmentally more advanced at embryonic day 5 than B6 embryos. eCG, equine chorionic gonadotrophin; $h C G$, human chorionic gonadotrophin. 
Mating was confirmed by the presence of a vaginal plug (day 1 of pseudopregnancy). Blastocysts were transferred to day 4 pseudopregnant recipients approximately 90.5-91.5 h after initiation of culture (embryonic day 5, Fig. 1). The surgery was performed under general anaesthesia induced by i.p. injection of 2\% Avertin (2,2,2-tribromoethanol in 2-methyl2-butanol, diluted to $2 \%$ solution in $\mathrm{H}_{2} \mathrm{O} ; 0.015 \mathrm{~mL} / \mathrm{g}$ body weight). The uterine horns were exposed via a dorsal incision and five blastocysts were transferred per uterine horn (e.g. 10 blastocysts per recipient) using a glass pipette specifically designed for embryo transfer (Swemed AB, Billdal, Sweden). Blastocysts were randomly allocated and transferred to a minimum of two recipients on any given day and these were from at least two different treatment groups. Surplus CBAB6F2 blastocysts were stored in Qiagen RNeasy Plus RNA lysis buffer (Qiagen) and frozen at $-80^{\circ} \mathrm{C}$ for subsequent RNA extraction and microarray analysis.

\section{Analysis of implantation, pregnancy rates and postnatal growth}

Recipient mice were killed at midday on day 8 of pregnancy (4 days post-surgery; C57Bl/6 control: $n=11, \mathrm{IGF} 2: n=10$, $\mathrm{U}+\mathrm{P}: n=12, \mathrm{IGF} 2+\mathrm{U}+\mathrm{P}: n=11, \mathrm{CBAB} 6 \mathrm{~F} 1$ control: $n=14$, IGF2: $n=11, \mathrm{U}+\mathrm{P}: n=13, \mathrm{IGF} 2+\mathrm{U}+\mathrm{P}: n=11)$ or on day 18 of pregnancy (14 days post-surgery; control: $n=8$, IGF2: $n=14, \mathrm{U}+\mathrm{P}: n=14, \mathrm{IGF} 2+\mathrm{U}+\mathrm{P}: n=13)$. Only the CBAB6F1 recipients were assessed at day 18 and postnatally due to poor pregnancy rates at this time in B6 mice. The number of viable and resorbing implantation sites were recorded at day 8 and the pregnancy rate, foetal and placental weights, litter size and maternal body composition were recorded for those killed at day 18. Additional recipients (control: $n=19$, IGF2: $n=20, \mathrm{U}+\mathrm{P}: n=17, \mathrm{IGF} 2+\mathrm{U}+\mathrm{P}: n=20$ ) were allowed to give birth naturally and the length of gestation, litter size and birthweights were recorded. Postnatal growth trajectory of male and female CBAB6F2 offspring was assessed within $24 \mathrm{~h}$ of birth, at 3, 5, 8, 12 and 16 weeks after birth $(n=45-51$ in each group for each sex). Birthweight corrected for gestational age was not different between groups. At 3 weeks of age, the pups were weaned and the sexes separated after which gender-based analyses were performed on postnatal growth. Full body composition analyses were undertaken at 16 weeks. Other male and female CBAB6F2 offspring were allowed to grow until 12 weeks when they were mated within embryo culture groups and birthweight and litter size were assessed ( $n=8-10$ in each group).

\section{Microarray}

CBAB6F2 blastocysts cultured in control (4 biological replicates of 350 pooled blastocysts), and IGF2 $+U+P$ treatment media (4 biological replicates of 350 pooled blastocysts) were extracted using the Qiagen RNeasy Plus Kit according to the manufacturers protocol. Microarray analyses using Agilent SurePrint G3 Mouse GE $(8 \times 60 \mathrm{~K})$ arrays were provided by a commercial service provider, The Ramaciotti Centre for Gene Function Analysis (Sydney, NSW, Australia), who provided the authors with the raw data. Agilent Low RNA Input Linear Amplification Kit PLUS (Agilent Technologies) was used to amplify the starting amount of RNA (50 ng). The four replicates for each treatment were split evenly across two separate SurePrint slides.

The raw array data were analysed in $\mathrm{R}$ version 2.15 using the limma module version 3.12. Background correction was performed using a normal + exponential model with an offset of 10 intensity units. Data were normalized between arrays using the quantile method. Genes that had fewer than two arrays with significant difference from background were excluded. Significance was calculated by fitting of a linear model for the treatment vs control contrasts with Bayesian estimation of variance. The probes with the top $500 P$-values were retained for further analyses. Differentially expressed genes were defined as those with an adjusted $P$-value $<0.05$.

The Database for Annotation, Visualization and Integration Discovery (DAVID) Functional Annotation tool (Huang et al. 2007) version 6.7 was used to test for statistically overrepresented gene ontology terms in the IGF2 $+U+P$ treatment vs control microarray gene dataset. Analysis was run using the highest classification stringency. The PANTHER Classification System (Mi et al. 2013) statistical over-representation test (at http://pantherdb.org/, version 10) and the InnateDB database (at http://www.innatedb.com/) were also used to interpret the differentially expressed gene list. The oPOSSUM v3.0 system was used for identifying over-represented transcription factorbinding sites (TFBS) in sets of co-expressed genes. Upon querying the web-based interface at opossum.cisreg.ca/ with a list of co-expressed genes, oPOSSUM retrieves the TFBS

Table 1 Effect of IGF2, uPA and plasminogen on blastocyst development from the 2-cell stage at 10:30h on embryonic day 5 (90.5-91.5 h of culture).

\begin{tabular}{|c|c|c|c|c|c|c|}
\hline & & Expanded (\%) & Hatching (\%) & Hatched $(\%)$ & Hatching or hatched $(\%)$ & Total blastocyst (\%) \\
\hline \multirow[t]{4}{*}{ B6 } & Control $(n=266)$ & $9.46( \pm 1.6)$ & $57.2( \pm 3.9)$ & $9.4( \pm 3.1)$ & $66.7( \pm 3.3)$ & $75.4( \pm 3.1)$ \\
\hline & IGF2 $(n=280)$ & $11.4( \pm 2.5)$ & $70.2( \pm 3.1)$ & $3.0( \pm 1.9)$ & $73.2( \pm 3.0)$ & $84.3( \pm 1.5)^{*}$ \\
\hline & $\mathrm{U}+\mathrm{P}(n=289)$ & $13.8( \pm 2.8)$ & $67.9( \pm 3.5)$ & $3.0( \pm 1.4)$ & $71.0( \pm 3.7)$ & $84.9( \pm 1.8)^{*}$ \\
\hline & IGF2 + U +P $(n=288)$ & $8.6( \pm 1.7)$ & $73.8( \pm 3.3)$ & $4.3( \pm 2.0)$ & $78.1( \pm 2.8)^{* *}$ & $86.5( \pm 3.2)^{*}$ \\
\hline \multirow[t]{4}{*}{ CBAB6F2 } & Control $(n=1827)$ & $13.4( \pm 1.8)$ & $80.0( \pm 2.1)$ & $0.7( \pm 0.3)$ & $80.7( \pm 2.0)$ & $94.1( \pm 0.8)$ \\
\hline & IGF2 $(n=1869)$ & $13.5( \pm 1.8)$ & $79.7( \pm 1.9)$ & $0.5( \pm 0.3)$ & $80.1( \pm 1.9)$ & $93.6( \pm 0.9)$ \\
\hline & $\mathrm{U}+\mathrm{P}(n=1697)$ & $14.1( \pm 2.8)$ & $79.6( \pm 2.8)$ & $1.3( \pm 0.6)$ & $80.9( \pm 2.9)$ & $95.0( \pm 0.7)$ \\
\hline & IGF2 + U +P $(n=1809)$ & $12.7( \pm 1.9)$ & $80.3( \pm 2.3)$ & $1.3( \pm 0.4)$ & $81.5( \pm 2.2)$ & $94.2( \pm 0.9)$ \\
\hline
\end{tabular}

Data are presented as mean \pm standard error of the mean ( \pm S.E.M.). Total blastocysts include early blastocysts as well as expanded, hatching and hatched blastocysts. $U+P$ : uPA and plasminogen, IGF2 $+U+P$ : IGF2, uPA and plasminogen. ANOVA $* * P=0.018$ IGF2 $+U+P$ treatment vS control, ${ }^{*} P<0.02$ for each treatment vs control. B6: $n=11$ replicates of $8-462$-cell embryos per treatment. CBAB6F2: $n=38-39$ replicates of 2-113 2-cell embryos per treatment. 
counts for each gene in the list and computes two statistics (Z-score, Fisher score) to measure over-representation of TFBSs in the set relative to a background comprising all genes in the oPOSSUM database. The Z-score takes into account the number of TFBS in a gene while the Fisher score counts TFBSs as present or absent (Ho Sui et al. 2005).

\section{Statistical analyses}

To analyse differences in embryo development, univariate analysis of variance (ANOVA) using the day of the replicate as a covariate was performed. Differences in implantation and pregnancy rates were assessed using chi square analyses. To determine the effect of treatment on litter size after embryo transfer, univariate ANOVA with the Bonferroni post hoc procedure was used. Statistical analyses were conducted using SPSS software (IBM SPSS Statistics version 21) except when using chi square, in which case GraphPad Prism (GraphPad Prism version 6) was used. Differences were considered to be significant if $P<0.05$.

\section{Results}

Effect of IGF2, uPA and plasminogen in combination on embryo development, implantation and day 8 pregnancy rates in the $B 6$ strain

\section{Embryo development}

Treatment with IGF2 $+\mathrm{U}+\mathrm{P}$ increased the percentage of $\mathrm{B} 6$ embryos that were hatching or had hatched after $90.5-91.5 \mathrm{~h}$ of culture by $17 \%$ compared to control $(P=0.018$, Table 1$)$. Treatment with IGF2, $\mathrm{U}+\mathrm{P}$ and $\mathrm{IGF} 2+\mathrm{U}+\mathrm{P}$ increased the percentage of $\mathrm{B} 6$ embryos that had developed from 2-cell to the blastocyst stage after $90.5-91.5 \mathrm{~h}$ of culture by $11-14 \%$ compared to control $(P<0.02$, Table 1$)$.

\section{Pregnancy and implantation rates at day 8}

Analysis of B6 pregnancy rates after embryo transfer found that both $\mathrm{U}+\mathrm{P}$ and $\mathrm{IGF} 2+\mathrm{U}+\mathrm{P}$ significantly increased the percentage of mice pregnant at day 8 by over $34 \%$ and $82 \%$, respectively, compared to control (Fig. 2A). The number of implantation sites as a percentage of embryos transferred was significantly increased for the IGF2 $+\mathrm{U}+\mathrm{P}$ treatment group (Fig. 2B).

Effect of IGF2, uPA and plasminogen in combination on embryo development, implantation and days 8 and 18 pregnancy rates in the $C B A B 6 F 2$ strain

\section{Embryo development}

The percentage of CBAB6F2 embryos that developed from the 2-cell to the blastocyst stage after 90.5-91.5 h of culture was not altered by treatment (Table 1 ). CBAB6F2 controls had a high rate of development to blastocysts $(94 \%)$ at this time, compared with only $75 \%$ of B6 embryos reaching blastocyst stage by this time.

As CBAB6F2 embryos clearly developed at a faster rate than $\mathrm{B} 6$ embryos and there was a predominance of hatching blastocysts after 90.5-91.5 h of culture, we performed embryo transfers to recipient females in the afternoon of day 4 (after $72 \mathrm{~h}$ of culture) to eliminate this confounder. In this subset of embryos there was a lower percentage of hatching embryos (control: $8.9 \% \pm 2.4$, IGF2: $13.0 \% \pm 4.7, \quad \mathrm{U}+\mathrm{P}: \quad 14.2 \% \pm 2.8, \quad$ IGF2 $+\mathrm{U}+\mathrm{P}$ : $13.0 \pm 2.8)$ compared with embryos cultured for $90.5-$ $91.5 \mathrm{~h}$ (79.6-80.3\% hatching, Table 1). The percentage of 2-cell embryos that had developed into blastocysts at this stage was between 14 and $17 \%$ and was not different between groups.

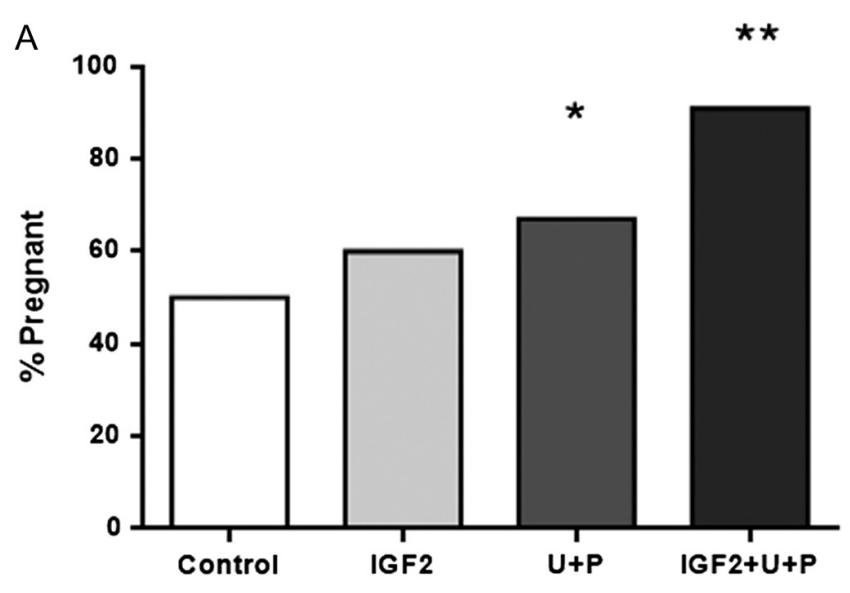

B

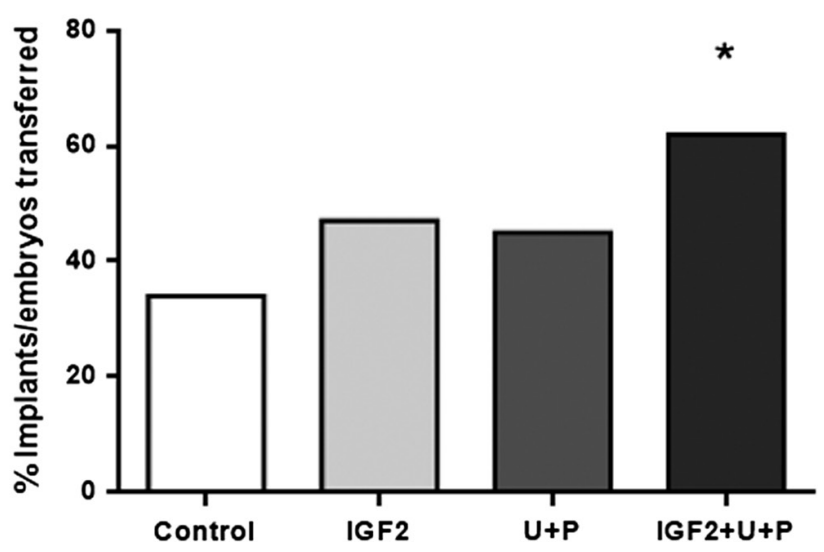

Figure 2 Effect of IGF2, uPA and plasminogen in combination on embryo development, implantation and day 8 pregnancy rates in the B6 strain. (A) Treatment of embryos with either $\mathrm{U}+\mathrm{P}$ or with IGF2 $+\mathrm{U}+\mathrm{P}$ increased the percentage of mothers pregnant at day 8 following early day 5 embryo transfer by over $34 \%\left({ }^{*} P=0.015\right)$ and $82 \%\left({ }^{* *} P=0.0001\right)$, respectively, compared to control ( $n=10-12$ mothers in each group). (B) Treatment with IGF2 $+\mathrm{U}+\mathrm{P}$ increased the number of implantation sites per embryos transferred at day 8 following embryo transfer on day 5 by $82 \%(P<0.05)$. ( $n=10-12$ mothers in each group.) 

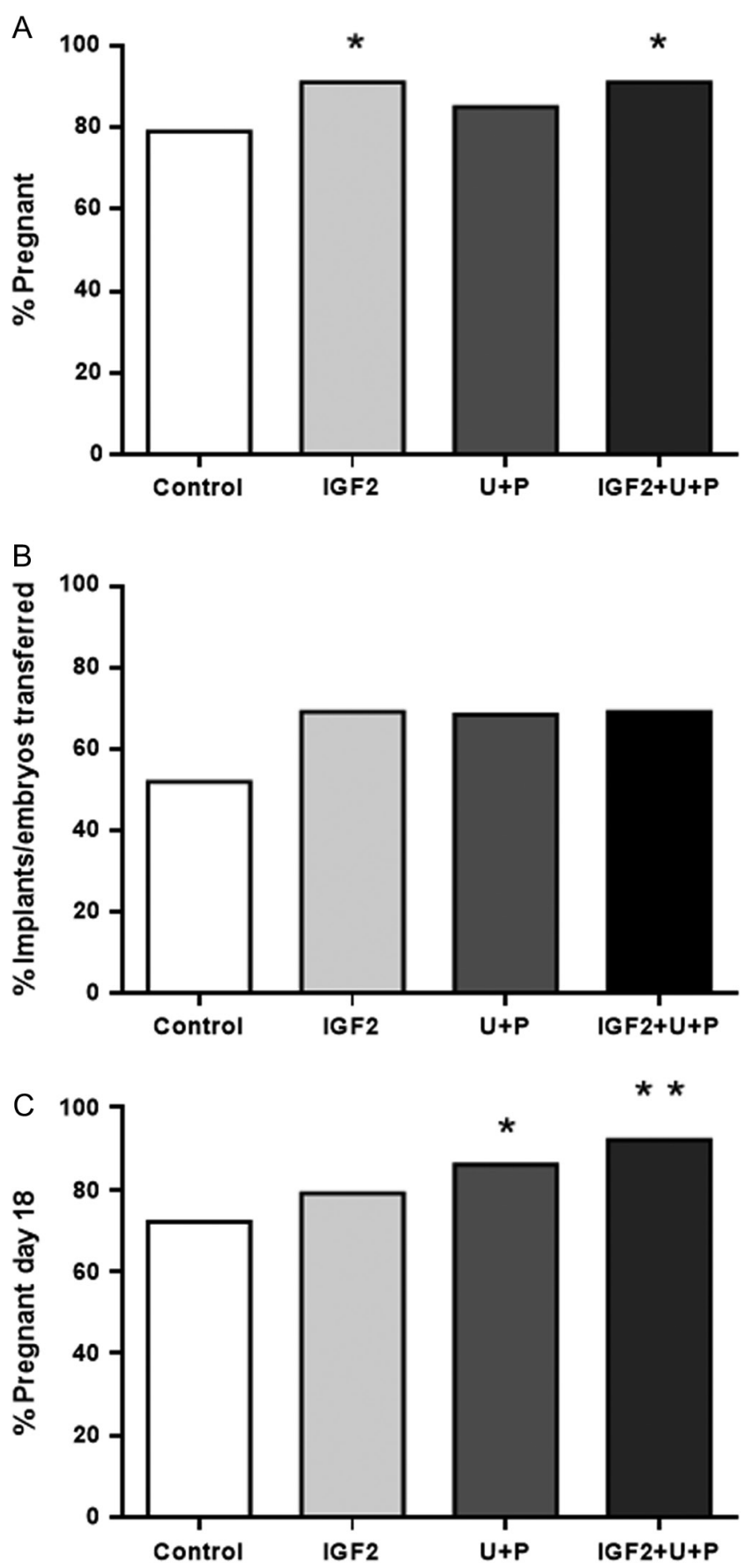

Figure 3 Effect of IGF2, uPA and plasminogen in combination on embryo development, implantation and day 8 and 18 pregnancy rates in the CBA F2 strain. (A) Treatment of embryos with either IGF2 alone or with the combination of IGF $2+U+P$ increased the percentage of mothers pregnant at day 8 following late day 4 embryo transfer by nearly $16 \%$ compared to control ( $P=0.0281$ both). Culture of embryos in media supplemented with uPA plus plasminogen did not significantly improve pregnancy rate at day 8 of pregnancy $n=10-14$ mothers in each group. (B) The number of implantation sites per embryos transferred at day 8 following embryo transfer on day 5 was increased by each treatment by up to $33 \%$ but these were not statistically significant. ( $n=12-15$ mothers in each group.) (C) Culturing embryos in media supplemented with IGF2 had
When comparing the embryo development of B6 with CBAB6F2 embryos at 90.5-91.5 h, the CBAB6F2 embryos had higher rates of total blastocysts $(P=0.019)$, per cent hatching or hatched $(P=0.031)$ and per cent hatching $(P=0.038)$. The percentage of embryos at the expanded and hatched blastocyst stages did not differ between strains.

\section{Pregnancy and implantation rates at day 8}

Culture of CBAB6F2 embryos with IGF2 significantly increased the number of mothers that were pregnant 4 days after embryo transfer at day 8 by $16 \%(n=10 / 11$, $91 \%)$ compared to controls $(n=11 / 14,79 \% ; P=0.028)$ (Fig. 3A). Treatment of embryos with IGF2 $+\mathrm{U}+\mathrm{P}$ also significantly increased the number of mothers that were pregnant 4 days after embryo transfer by $16 \%(n=10 / 11$, $91 \%$ ) compared to controls $(n=11 / 14,79 \% ; P<0.028)$ while treatment with $\mathrm{U}+\mathrm{P}$ did not alter the number of mothers that were pregnant $(n=11 / 13,85 \%)$ compared to controls (Fig. 3A).

Although the number of implantation sites per embryo transferred was increased by up to $39 \%$ by the treatments compared with control, these were not statistically significant (Fig. 3B).

\section{Pregnancy rates at day 18}

Culture of CBAB6F2 embryos with IGF2 did not alter the percentage of mothers that were pregnant at day $18(n=11 / 14,79 \%)$ compared to controls $(n=13 / 18$, $72 \%$; NS) (Fig. 3C). Treatment of embryos with $U+P$ significantly increased the number of mothers that were pregnant 14 days after embryo transfer by $18.7 \%$ $(n=12 / 14,86 \%)$ compared to controls $(n=13 / 18$, $72 \% ; P=0.023)$ while treatment with IGF2 $+\mathrm{U}+\mathrm{P}$ increased the proportion of mothers that were pregnant 14 days after embryo transfer by $27.8 \%(11 / 12,92 \%)$ compared to controls $(n=13 / 18,72 \% ; P=0.0004)$ (Fig. 3C). CBAB6F1 mice were 2.3 times more likely to still be pregnant at day 18 following treatment of CBAB6F2 embryos with $\mathrm{U}+\mathrm{P}$ compared to controls (Odds ratio (OR): 2.389, 95\% confidence interval 1.17-4.879). Culturing embryos in the combination of IGF $2+U+P$ increased the probability of CBAB6F1 recipients being pregnant at day 18 just prior to term by almost 4.5 times compared to controls (OR: 4.472, 95\% Cl: 1.922-10.40).

no effect on the percentage of mothers pregnant 14 days after embryo transfer on day 18 of pregnancy just prior to term. However, culturing embryos in media supplemented with a combination of UPA and plasminogen significantly increased the percentage of mothers pregnant on day 18 of pregnancy by $18.7 \%$ compared to controls $\left({ }^{*} P=0.023\right)$. Culturing embryos in media supplemented with a combination of IGF2 $+U+P$ significantly increased the percentage of mothers pregnant at day 18 by $27.8 \%$ compared to controls $(* * P=0.0004)$. 
Effect of embryo culture in IGF2, uPA and plasminogen on CBAB6F2 strain foetal weight, placental weight and litter size

In those mice that remained pregnant at day 18 of pregnancy ( 14 days after embryo transfer), litter size was not affected by culture of embryos in different media formulations (control: $5.11 \pm 0.870$, IGF2: $4.71 \pm 0.957$, $U+P: 5.50 \pm 0.776, I G F 2+U+P: 6.23 \pm 0.709)$.

Foetal weight at day 18 was increased by $6.9 \%$ following culture of CBAB6F2 embryos in media supplemented with IGF2 compared to controls $(910 \pm 15 \mathrm{mg}$ vs $851 \pm 12 \mathrm{mg}, \quad P=0.008)$. Embryo culture neither with $\mathrm{U}+\mathrm{P}$ nor with IGF2 $+\mathrm{U}+\mathrm{P}$ affected foetal weight at day 18 of gestation $(850 \pm 14 \mathrm{mg}$ and $860 \pm 13 \mathrm{mg}$, respectively). Placental weight at day 18 of gestation was similar between treatment groups (control: $120 \pm 3 \mathrm{mg}$, IGF2: $126 \pm 3 \mathrm{mg}$, U + P: $125 \pm 3 \mathrm{mg}$, IGF2 + U +P: $118 \pm 3 \mathrm{mg}$ ). The foetal weight:placental weight ratio, a measure of placental efficiency, was similar between groups (control: $7.176 \pm 0.003$, IGF2: $7.431 \pm 0.003, \quad U+P: \quad 7.088 \pm 0.003, \quad I G F 2+U+P:$ $7.426 \pm 0.003)$.

Effect of embryo culture in IGF2, uPA and plasminogen in combination on CBAB6 strain litter size at birth, gestational age, birthweight and postnatal growth

Culture of CBAB6F2 embryos in media formulations containing IGF2, UPA and plasminogen or IGF2 $+\mathrm{U}+\mathrm{P}$ did not significantly affect litter size, birthweight or gestational age at birth compared with control $(P>0.05$, Table 2).

As IGFs can elicit growth-promoting effects and overstimulation by IGF2 is implied in several overgrowth conditions (Sara \& Hall 1990, Hedborg et al. 1994), we assessed postnatal growth and body composition at 16 weeks. There was no effect of embryo culture media formulation on postnatal growth of CBAB6F2 offspring to 16 weeks after birth $(P>0.05$, Fig. 4).

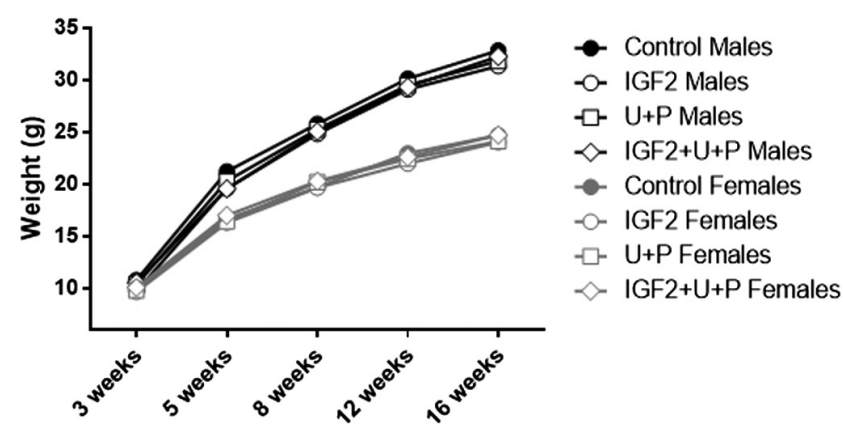

Figure 4 Effect of embryo culture in IGF2, uPA and plasminogen in combination on CBA strain postnatal growth. There was no effect of embryo culture in different media formulations on postnatal growth trajectory. Weight of males at weening ( 3 weeks) was similar to that of females but after this the males ( $n=44-60$ in each group) grew faster than females ( $n=45-51$ in each group).
Full body composition analyses were performed on CBAB6F2 offspring killed at 16 weeks of age. Offspring liver, kidneys, spleen, heart, lungs and parametrial or epididymal adipose tissue were dissected from the body and their weights recorded and relative weights calculated (weight as a percentage of total body weight). In females (Table 3), liver weight was decreased in all three treatment groups compared with control $(\downarrow 11.3 \%$ in IGF2, $\downarrow 12.0 \%$ in $\mathrm{U}+\mathrm{P}$ and $\downarrow 8.4 \%$ in IGF2 $+\mathrm{U}+\mathrm{P}$, $P<0.044$ for all). Liver weight as a percentage of total body weight was also decreased in all treatment groups $(P<0.009)$. In males (Table 4$)$, lung weight was decreased in $\mathrm{U}+\mathrm{P}$ and $\mathrm{IGF} 2+\mathrm{U}+\mathrm{P}$ treatment groups but this was not significant when lung weight was expressed as a percentage of total body weight. Epididymal fat was reduced by $36 \%$ in the IGF2 treated group compared with control.

\section{Effect of embryo culture in IGF2, UPA and plasminogen on subsequent reproductive capacity in CBAB6F2 offspring}

A subset of male and female CBAB6F2 offspring (nonlittermates) were mated at 12 weeks of age within original treatment groups to determine whether embryo culture in media supplemented with combinations of IGF2, uPA and plasminogen had any effect on subsequent reproductive capacity of offspring. Litter size of CBAB6F2 offspring was not different between embryo culture groups (Fig. 5). Birthweights and weights at 3 weeks of age for CBAB6F3 offspring were also not different between embryo culture groups (Table 5, $P>0.05)$.

\section{Microarray}

Interestingly, pregnancy rates at both days 8 and 18 were improved by IGF $2+\mathrm{U}+\mathrm{P}$ treatment of CBAB6F2 embryos, despite no apparent effects on the rate of embryo development to the blastocyst stage. To determine whether any changes at the gene expression level were induced by IGF2 $+\mathrm{U}+\mathrm{P}$ treatment, we performed microarray analysis on day 4 CBAB6F2 blastocysts. After correction for multiple testing, only five genes were differentially expressed between control blastocysts and those cultured in media with IGF2 + U + P treatment. Those genes were PDZ domain containing 4

Table 2 Embryo culture in IGF2, uPA and plasminogen had no effect on gestational age, litter size or birthweight of CBAB6F2 pups.

\begin{tabular}{lcccc}
\hline $\begin{array}{l}\text { Embryo culture } \\
\text { treatment group }\end{array}$ & $\boldsymbol{n}$ & $\begin{array}{c}\text { Mean gestational } \\
\text { age (days) }\end{array}$ & $\begin{array}{c}\text { Mean litter } \\
\text { size }\end{array}$ & $\begin{array}{c}\text { Birthweight } \\
(\mathrm{g})\end{array}$ \\
\hline Control & 19 & $20.21( \pm 0.123)$ & $6.16( \pm 0.473)$ & $1.456( \pm 0.019)$ \\
IGF2 & 20 & $19.90( \pm 0.161)$ & $6.60( \pm 0.545)$ & $1.362( \pm 0.018)$ \\
U+P & 17 & $20.24( \pm 0.182)$ & $5.88( \pm 0.506)$ & $1.424( \pm 0.021)$ \\
IGF2 + U + P & 21 & $20.14( \pm 0.125)$ & $6.15( \pm 0.393)$ & $1.461( \pm 0.019)$ \\
\hline
\end{tabular}

Values shown are mean \pm standard error of the mean ( \pm S.E.M.). 


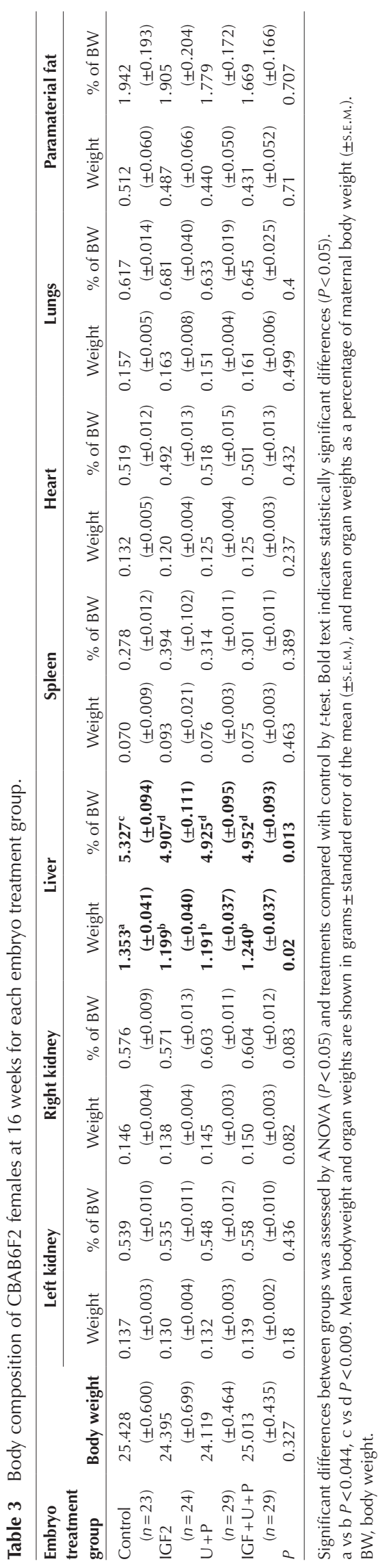

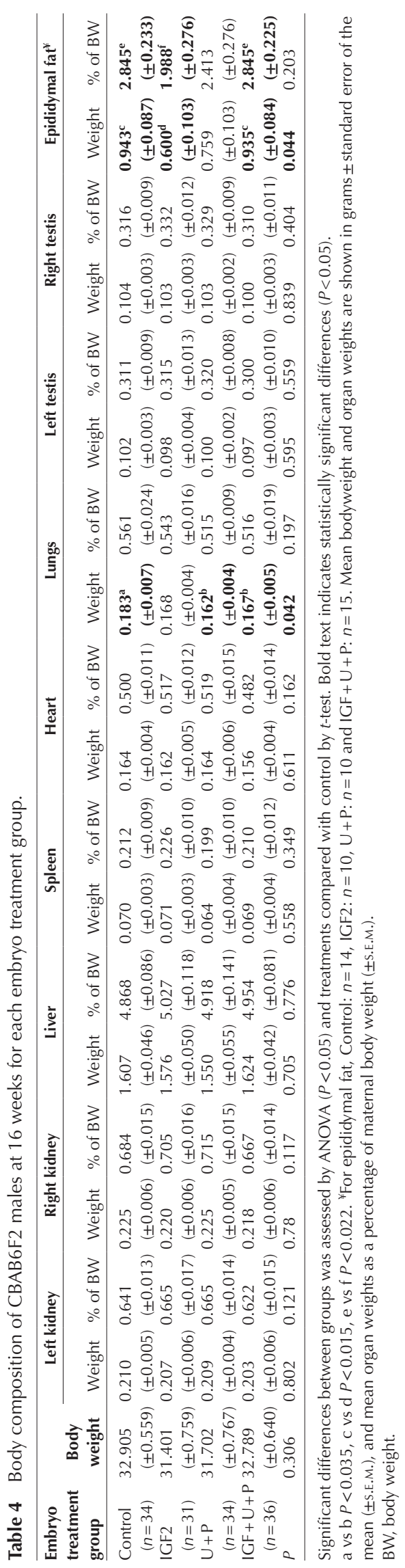

www.reproduction-online.org 
Table 5 Effect of embryo culture in IGF2, uPA and plasminogen on CBAB6F3 birthweight and weight at 3 weeks old.

\begin{tabular}{ccc}
\hline & Birthweight $(\mathrm{g})$ & Weight at $\mathbf{3}$ weeks $(\mathrm{g})$ \\
\hline Control & $1.40( \pm 0.025)$ & $9.571( \pm 0.192)$ \\
$n$ & 68 & 64 \\
IGF2 & $1.446( \pm 0.015)$ & $9.470( \pm 0.150)$ \\
$n$ & 74 & 66 \\
$\mathrm{U}+\mathrm{P}$ & $1.402( \pm 0.016)$ & $9.305( \pm 0.125)$ \\
$n$ & 85 & 82 \\
IGF2 $+\mathrm{U}+\mathrm{P}$ & $1.365( \pm 0.019)$ & $9.313( \pm 0.172)$ \\
$n$ & 82 & 78 \\
\hline
\end{tabular}

Data are mean \pm standard error of the mean ( \pm S.E.M.).

( $P d z d 4$; fold change (FC) 0.56, $P=0.019$ ), cordon-bleu WH2 repeat (Cobl; FC: 0.58, $P=0.019)$, follistatin-like 1 (Fst11; FC: 0.58, $P=0.019)$ reticulocalbin 1 (Rcn 1; FC: $0.60, P=0.037$ ) and mesoderm-specific transcript (Mest; FC: $0.63, P=0.040$ ).

In order to understand further how treatment with IGF2 + U + P affects embryo development and despite there being only five differentially expressed genes after correction for multiple testing, we analysed the top 500 probes (386 genes), sorted by $P$-value, for overrepresented terms in gene ontology using three methods: DAVID, PANTHER and InnateDB, and oPOSSUM analysis to identify common TFBS for the genes.

\section{DAVID}

Functional Annotation Analysis revealed that cellular chemical homeostasis (GO:0055082) and cellular ion homeostasis-associated genes (GO:0006873) were significantly over-represented $(P=0.035$ and $P=0.043$ respectively). Seventeen identical genes were associated with both ontologies. These are shown with their respective fold changes and $P$-values in Table 6 .
When the fold changes were considered, it appeared that zinc and iron uptake may be increased and zinc ion efflux and metallothionein expression decreased following embryo culture in IGF2 + U + P.

\section{PANTHER}

Statistical over-representation test of 248 mapped genes in Panther indicated that amino acid transport-associated genes were affected by IGF2 $+\mathrm{U}+\mathrm{P}$ treatment compared with control. This corresponded with downregulation of 6 members of the solute carrier (Slc) family: sodiumcoupled neutral amino acid transporter 2 (S/c38a2; FC: $0.73, P=0.002)$, excitatory amino acid transporter 1 (S/C1a3; FC: $0.68, P=0.00009$ ), large neutral amino acids transporter small subunit 1 (S/C7a5; FC: 0.64, $P=0.0006), M C G 3105$, isoform CRA_a (S/c5a4b; FC: $0.72, \quad P=0.0047)$, high-affinity cationic amino acid transporter 1 (S/C7a1; FC: 0.65, $P=0.0014$ ) and cationic amino acid transporter 3 (Slc7a3; FC: 0.6, $P=0.0006$ ).

\section{Innate $D B$}

Three hundred and seventy-five of the genes in the IGF $2+\mathrm{U}+\mathrm{P}$ vs control gene expression microarray dataset were submitted for gene ontology overrepresentation analysis using InnateDB at http://www. innatedb.com/ (Breuer et al. 2013). The top three most significant over-represented biological processes associated with the genes in the dataset were amino acid transmembrane transport ( 6 genes; S/C1a5, S/c38a2, Slc38a5, S/c7a1, S/c7a3, Slc7a5, $P=0.0025)$, cellular zinc ion homeostasis (4 genes, Mt1, Mt2, Slc30a1, S/c39a4, $P=0.015$ ) and high-density lipoprotein particle clearance (3 genes; Apoa2, Apom, Scarb1, $P=0.017$ ).

Table 6 Genes identified by DAVID Functional Annotation Analysis associated with cellular chemical homeostasis (GO:0055082) and cellular ion homeostasis (GO:0006873) to be affected by IGF2 $+U+P$ treatment compared with control, shown with their respective differential gene expression fold change and $P$ values.

\begin{tabular}{|c|c|c|c|c|}
\hline Gene symbol & Gene & Fold change & $\boldsymbol{P}$ (unadjusted) & $\boldsymbol{P}$ (adjusted) \\
\hline Slc30a 1 & Solute carrier family 30 (zinc transporter), member & 0.5944 & 0.0011 & 0.2699 \\
\hline Pth $1 r$ & Parathyroid hormone 1 receptor & 0.6461 & 0.0003 & 0.1730 \\
\hline Grik3 & Glutamate receptor, ionotropic, kinate 3 & 0.6642 & 0.0045 & 0.4231 \\
\hline Nrg1 & Neuregulin 1 & 0.6850 & 0.0005 & 0.2104 \\
\hline Bak1 & BCL2-antagonist/killer 1 & 0.7009 & $6.4 \mathrm{E}-05$ & 0.1057 \\
\hline$F 2 r$ & Coagulation factor II (thrombin) receptor & 0.7026 & 0.0049 & 0.4404 \\
\hline Adora 1 & Adenosine A1 receptor & 0.7242 & 0.0010 & 0.2649 \\
\hline Mt1 & Metallothionein 1 & 0.7547 & 0.0019 & 0.3316 \\
\hline Kcnh2 & $\begin{array}{l}\text { Similar to potassium channel erg1a; potassium voltage-gated channel, } \\
\text { subfamily } \mathrm{H} \text { (eag-related), member } 2\end{array}$ & 0.7609 & 0.0044 & 0.4223 \\
\hline Mt2 & Metallothionein 2 & 0.7743 & 0.0057 & 0.4632 \\
\hline Aqp 11 & Aquaporin 11 & 0.7935 & 0.0007 & 0.2406 \\
\hline$P 2 r \times 4$ & Purinergic receptor $\mathrm{P} 2 \mathrm{X}$, ligand-gated ion channel 4 & 0.8054 & 0.0050 & 0.4428 \\
\hline Best2 & Bestrophin 2 & 1.2230 & 0.0057 & 0.4641 \\
\hline Grin $2 a$ & $\begin{array}{l}\text { Similar to } N \text {-methyl-D-aspartate receptor channel subunit epsilon } 1 \text {; } \\
\text { glutamate receptor, ionotropic, NMDA2A (epsilon } 1 \text { ) }\end{array}$ & 1.2339 & 0.0066 & 0.4897 \\
\hline $\operatorname{TfrC}^{\dagger}$ & Transferrin receptor & 1.3246 & 0.0010 & 0.2649 \\
\hline Rgn & Regucalcin & 1.3359 & 0.0020 & 0.1338 \\
\hline Slc39a4 & Solute carrier family 39 (zinc transporter), member 4 & 1.4109 & 0.0026 & 0.3672 \\
\hline $\operatorname{TfrC}^{\dagger}$ & Transferrin receptor & 1.4196 & 0.0046 & 0.4275 \\
\hline
\end{tabular}

†2 different Tfrc probes (A_52_P228236 and A_51_P167876) indicated differential expression of Tfrc. 


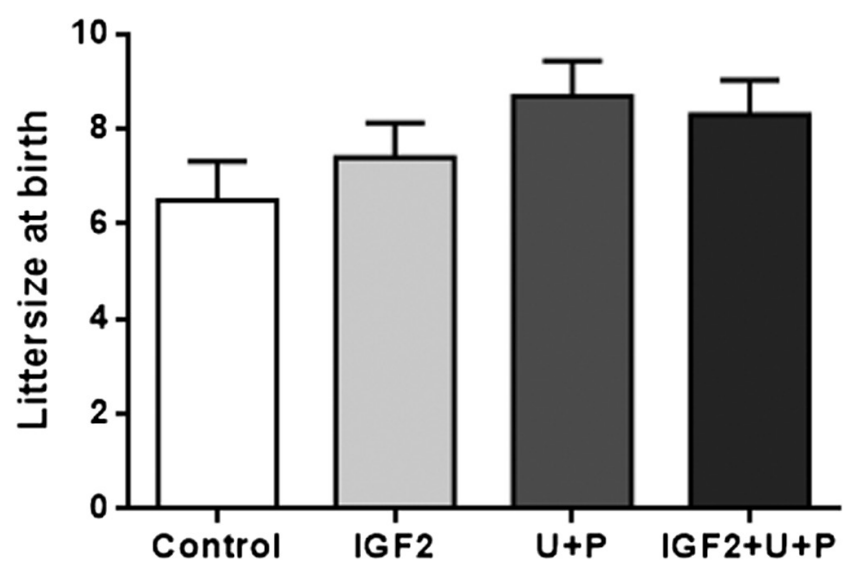

Figure 5 Effect of embryo culture in IGF2, uPA and plasminogen on litter size of CBA F2 offspring. Litter size at birth was not significantly affected following mating of CBA F2 offspring, which had been cultured as embryos in supplemented media (Control: $n=8$; IGF2: $n=10 ; \mathrm{U}+\mathrm{P}: n=10 ; \mathrm{IGF} 2+\mathrm{U}+\mathrm{P}: n=10$ ).

\section{OPOSSUM}

Three-hundred and seventy-five of 386 genes in the IGF2 $+\mathrm{U}+\mathrm{P}$ vs control gene expression microarray dataset were analysed by oPOSSUM for significantly over-represented TFBS. Two hundred and sixty-four $(70.4 \%)$ of the genes contained a binding site for the transcription factor Sp1 (Z-score 42.3, Fisher Score $34.1)$, which is known to regulate gene expression in the preimplantation mouse embryo and increase in abundance during blastocyst development (Worrad \& Schultz 1997). The next most significant TFs were MZF $(74.4 \%$ of genes, Z-score 34.0, Fisher score $26.1)$ and KIf4 (74.4\% of genes, Z-score 29.5 , Fisher score 28.5).

\section{Discussion}

The addition of IGF2, UPA and plasminogen, in combination, to embryo culture media improved blastocyst development in the B6 mouse strain and increased subsequent implantation and pregnancy rates following embryo transfer. The effects on a more reproductively 'robust' hybrid mouse strain, CBAB6, were less marked and the percentage of implantations per embryos transferred did not differ; however, the increased pregnancy rate observed at day 8 appeared to be sustained to day 18 in the IGF $2+\mathrm{U}+\mathrm{P}$ treated group.

Previously, addition of IGF2 to embryo culture media increased blastocyst development and the proportion of blastocysts hatching (Harvey \& Kaye 1992a,b, O'Neill 1997, Kurzawa et al. 2001, Lin et al. 2003, Pantaleon et al. 2003). The less pronounced effect of IGF2 on blastocyst development between this study and those preceding them may be because the present study utilized a sequential media system whereas previously only simple, one-step embryo culture media have been used. This change to a sequential media system has improved embryo culture and thus the effect of exogenous IGF2 may be somewhat diluted. The B6 embryo transfer experiments demonstrated that uPA plus plasminogen treatment, without IGF2, also increased the number of recipients that were pregnant following embryo transfer. Previously, plasminogen treatment alone has been shown to improve blastocyst development and hatching in mouse and sheep embryos (Menino \& O'Claray 1986, Menino et al. 1989) and such effects on blastocyst development were seen in the present study on B6 embryos with the addition of UPA and plasminogen.

We have shown that after $90.5 \mathrm{~h}$ of culture the combination of IGF2, uPA and plasminogen in the media significantly improved hatching and blastocyst development compared to all other groups in B6 embryos. Embryos of C57BL/6 mice grow more slowly and are considered to be more sensitive to culture conditions, which have been proposed to result from lower production of autocrine trophic ligands in vitro (Jin \& O'Neill 2014). CBAB6F2 blastocyst development could not be improved by any of these media formulations, which likely reflects the robustness of these embryos. These data suggest that IGF2, UPA and plasminogen act synergistically in embryo culture media to accelerate development of poor-quality embryos over and above that seen in media supplemented with these factors on their own or the combination of UPA and plasminogen.

The differences observed in the pregnancy rate for CBAB6F2 embryos compared to B6 embryos is likely due to the greater robustness of CBAB6F2 embryos compared with B6 embryos. As CBAB6F2 embryos grow faster than $\mathrm{B} 6$ embryos, and culture of CBAB6F2 embryos to embryonic day 5 made it very difficult to transfer them to pseudopregnant recipients, it was necessary to transfer these embryos to pseudopregnant recipients late on day 4 (after $72 \mathrm{~h}$ of culture) to avoid embryo loss at transfer due to blastocyst hatching. These differences highlight the possibility that embryo culture in media supplemented with a combination of IGF2, uPA and plasminogen may be particularly beneficial when the embryo's ability to implant is compromised.

Most importantly, the percentage of recipients pregnant at day 8 (4 days after transfer) was greatest for those embryos that had been cultured in the combination of all three factors compared to controls. For CBAB6F2 this proportion increased by nearly $16 \%$ while the implantation rate of $\mathrm{B} 6$ embryos that had been cultured with the combination of all three factors was increased by $34 \%$. Differences were also seen for IGF2 in CBAB6F2 embryos and for $\mathrm{U}+\mathrm{P}$ for the B6 mice (Fig. 2A and B). Day 8 is at a very early phase of placental development in the mouse with substantial placental trophoblast invasion of the maternal decidua underway, an important phase in human implantation/placentation 
too. The combination of IGF2, uPA and plasminogen may prove to enable in vitro cultured embryos to get over the hurdle of implantation.

In the CBAB6F2 mice, embryo development in controls is at such a high level that it seems unlikely that this can be improved upon. Nevertheless, the percentage of CBA mothers pregnant at days 8 and 18 following embryo transfer on day 4 is significantly greater in embryos cultured with IGF2 + UPA + plasminogen $(\mathrm{IGF} 2+\mathrm{U}+\mathrm{P})$ compared to the control media alone. So despite no observable difference in blastocyst development there may indeed be differences at the cellular and molecular levels that may explain improved pregnancy rates at days 8 and 18 .

Microarray analysis of IGF2 $+\mathrm{U}+\mathrm{P}$ treated CBAB6F2 embryos indicated that the genes Pdzd4, Cobl, Fstl1, Rcn 1 and Mest were significantly downregulated. As the changes in gene expression were modest and none of the five differentially expressed genes exceed a 2 -fold change, the results and their biological significance must be interpreted with some caution. The function of these genes in early embryo development is not known and they have no clear connection with enhanced embryo development post-transfer. Cobl is involved in neural tube formation (Carroll et al. 2003). A developmental role for Fstl1, a BMP4 signalling antagonist, has been demonstrated in early dorsoventral body axis establishment in zebrafish and in lung development in mice (Geng et al. 2011). Rcn1 encodes a calciumbinding protein localized to the endoplasmic reticulum lumen and is proposed to play a role in breast cancer cell invasiveness (Liu et al. 1997). The role of the Pdzd4 gene product in blastocyst development is currently unknown. Mest is an imprinted gene expressed only from the paternal allele during development. Disruption of the gene in mice causes embryonic growth retardation associated with reduced postnatal survival rates (Lefebvre et al. 1998). Mest expression in the mouse coincides with placental and decidual angiogenesis and is localized to the developing capillary endothelium (Mayer et al. 2000). Some studies have shown that assisted reproductive technology, such as IVF, influences DNA methylation and expression of MEST in humans and mice (Jahangiri et al. 2014). Embryo culture conditions have been shown to affect DNA methylation and imprinted gene expression in several animal models (Nelissen et al. 2012). Some differences in organ weights at 16 weeks were significant in the cohort of CBAB6F2 offspring that underwent post-mortem analysis. These findings require investigation in a larger cohort to determine what effects the treatments had on organ development.

Analysis of genes in the control vs IGF2 $+\mathrm{U}+\mathrm{P}$ dataset for over-represented gene ontology terms suggested that amino acid transport was affected by IGF2 $+U+P$ treatment, with downregulation of six members of the solute carrier (Slc) family. In the blastocyst morphology assessment, we found that IGF2 $+U+P$ treatment did not significantly increase the rate of progression to blastocyst stage (likely because it was already above $90 \%$ in CBAB6F2 controls). However, these alterations in amino acid transport suggest that there may be a difference in treated embryo nutrient metabolism at the gene expression level. In the early mouse embryo, amino acid transport systems are believed to be upregulated at the mRNA level when the transport they facilitate is physiologically required during that developmental stage (Van Winkle 2001). Interestingly, profiling the use of amino acids by developing embryos can predict viability and therefore IVF outcome (Sturmey et al. 2008). Lower amino acid turnover has been observed in developmentally competent day 2 human embryos compared with embryos that arrested (Houghton et al. 2002). The amino acids leucine, glycine and serine are less abundant in the medium of embryos from successful IVF cycles whilst asparagine and arginine are more abundant (Brison et al. 2004). This suggests that the increase in pregnancy rates at days 8 and 18 observed in the CBAB6 mice may be due to improved developmental competence, evident at the blastocyst stage as a differential amino acid uptake gene expression profile. The microarray analysis also indicated differential zinc transporter and metallothionein mRNA expression in the treated blastocysts. The SLC3OA 1 (zinc transporter 1) gene in particular is essential during early embryonic development in the mouse and functions to bring zinc into the embryonic environment during critical times of differentiation and growth (Andrews et al. 2004).

\section{Conclusion}

Development of mouse embryos in vitro and pregnancy success after embryo transfer were improved by treatment with IGF2 combined with uPA and plasminogen, but the effects observed in this study were largely strain specific. The effect on blastocyst development was seen only in the B6 mouse strain, which suffers from poor outcomes after in vitro culture and benefits from growth factor treatment. Embryos from different mouse species could have very different requirements for exogenous trophic support during in vitro culture. The mechanisms underlying the benefits of IGF2, uPA and plasminogen supplementation could be via IGF2R/uPAR interactions, as the IGF2R contains distinct binding sites for plasminogen and the uPAR (Braulke 1999). Further elucidation of the roles played by these receptors in implantation and placentation are important for our understanding of pregnancy and the aetiology of human pregnancy complications.

\section{Declaration of interest}

The authors have no conflicts of interest to declare except CTR was granted funds by MediCult A/s now ORIGIO A/s Denmark 
for initial experiments and provided embryo culture media to which the treatments were added in Adelaide for this research. However, MediCult played no role in experimental design or interpretation of the results.

\section{Funding}

C T R was granted funds by MediCult $\mathrm{A} / \mathrm{s}$ now ORIGIO $\mathrm{A} / \mathrm{s}$, Denmark, for initial experiments and provided embryo culture media to which the treatments were added in Adelaide for this research. However, MediCult played no role in experimental design or interpretation of the results. We also gratefully acknowledge the support of the National Health and Medical Research Council (NHMRC) of Australia for this research. This work was funded by a NHMRC Development Grant (GNT519374) awarded to C T R, M B N and J G T. A R H is supported by a NHMRC Australian Biomedical Training Fellowship (GNT1012784). C T R is supported by a NHMRC Senior Research Fellowship (GNT1020749). M B N is supported by a NHMRC Senior Research Fellowship (GNT1043825). J G T is supported by a NHMRC Senior Research Fellowship (GNT1077694). K G P is currently supported by an Australian Research Council Future Fellowship (FT150100179).

\section{Author contribution statement}

A $\mathrm{R} \mathrm{H}$ : microarray analysis, manuscript preparation; T B-M: microarray analysis, manuscript preparation; K G P: embryo culture and analysis, manuscript preparation; A P: embryo culture and analysis; S B: bioinformatic analyses; J Z: sample preparation for microarray analysis; M B N: study design and result interpretation; J G T: study design and result interpretation; C T R: study design and result interpretation, manuscript preparation.

\section{Acknowledgements}

We thank Simon Moretta for providing technical assistance with this work.

\section{References}

Aflalo ED, Sod-Moriah UA, Potashnik G \& Har-Vardi I 2004 Differences in the implantation rates of rat embryos developed in vivo and in vitro: possible role for plasminogen activators. Fertility and Sterility $\mathbf{8 1}$ (Supplement 1) 780-785. (doi:10.1016/j.fertnstert.2003.10.014)

Aflalo ED, Sod-Moriah UA, Potashnik G \& Har-Vardi I 2005 Expression of plasminogen activators in preimplantation rat embryos developed in vivo and in vitro. Reproductive Biology and Endocrinology 37. (doi:10.1186/1477-7827-3-7)

Aflalo ED, Sod-Moriah UA, Potashnik G \& Har-Vardi I 2007 EGF increases expression and activity of PAs in preimplantation rat embryos and their implantation rate. Reproductive Biology and Endocrinology 54. (doi:10.1186/1477-7827-5-4)

Andrews GK, Wang H, Dey SK \& Palmiter RD 2004 Mouse zinc transporter 1 gene provides an essential function during early embryonic development. Genesis 40 74-81. (doi:10.1002/gene.20067)

Axelrod HR 1985 Altered trophoblast functions in implantationdefective mouse embryos. Developmental Biology 108 185-190. (doi:10.1016/0012-1606(85)90021-1)
BraulkeT 1999Type-2 IGF receptor: a multi-ligand binding protein. Hormone and Metabolic Research 31 242-246. (doi:10.1055/s-2007-978725)

Breuer K, Foroushani AK, Laird MR, Chen C, Sribnaia A, Lo R, Winsor GL, Hancock RE, Brinkman FS \& Lynn DJ 2013 InnateDB: systems biology of innate immunity and beyond - recent updates and continuing curation. Nucleic Acids Research 41 D1228-D1233. (doi:10.1093/nar/ gks1147)

Brison DR, Houghton FD, Falconer D, Roberts SA, Hawkhead J, Humpherson PG, Lieberman BA \& Leese HJ 2004 Identification of viable embryos in IVF by non-invasive measurement of amino acid turnover. Human Reproduction 19 2319-2324. (doi:10.1093/humrep/ deh409)

Cannon MJ \& Menino AR Jr 1998 Changes in the bovine zona pellucida induced by plasmin or embryonic plasminogen activator. Molecular Reproduction and Development 51 330-338. (doi:10.1002/(SICI)10982795(199811)51:3<330::AID-MRD13>3.0.CO;2-6)

Carroll EA, Gerrelli D, Gasca S, Berg E, Beier DR, Copp AJ \& Klingensmith J 2003 Cordon-bleu is a conserved gene involved in neural tube formation. Developmental Biology 262 16-31. (doi:10.1016/S00121606(03)00323-3)

Chobotova K, Spyropoulou I, Carver J, Manek S, Heath JK, Gullick WJ, Barlow DH, Sargent IL \& Mardon HJ 2002 Heparin-binding epidermal growth factor and its receptor ErbB4 mediate implantation of the human blastocyst. Mechanisms of Development 119 137-144. (doi:10.1016/ S0925-4773(02)00342-8)

Desai N, Lawson J \& Goldfarb J 2000 Assessment of growth factor effects on post-thaw development of cryopreserved mouse morulae to the blastocyst stage. Human Reproduction 15 410-418. (doi:10.1093/ humrep/15.2.410)

Gallicchio MA, Kaun C, Wojta J, Binder B \& Bach LA 2003 Urokinase type plasminogen activator receptor is involved in insulin-like growth factor-induced migration of rhabdomyosarcoma cells in vitro. Journal of Cellular Physiology 197 131-138. (doi:10.1002/jcp.10352)

Gardner DK, Wale PL, Collins R \& Lane M 2011 Glucose consumption of single post-compaction human embryos is predictive of embryo sex and live birth outcome. Human Reproduction 26 1981-1986. (doi:10.1093/ humrep/der143)

Geng Y, Dong Y, Yu M, Zhang L, Yan X, Sun J, Qiao L, Geng H, Nakajima M, Furuichi T et al. 2011 Follistatin-like 1 (Fstl1) is a bone morphogenetic protein (BMP) 4 signaling antagonist in controlling mouse lung development. PNAS 108 7058-7063. (doi:10.1073/ pnas.1007293108)

Ghosh D, Najwa AR, Khan MA \& Sengupta J 2011 IGF2, IGF binding protein 1, and matrix metalloproteinases 2 and 9 in implantation-stage endometrium following immunoneutralization of vascular endothelial growth factor in the rhesus monkey. Reproduction 141 501-509. (doi:10.1530/REP-10-0475)

Godar S, Horejsi V, Weidle UH, Binder BR, Hansmann C \& Stockinger H 1999 M6P/IGFII-receptor complexes urokinase receptor and plasminogen for activation of transforming growth factor-beta1. European Journal of Immunology 29 1004-1013. (doi:10.1002/(SICI)1521-4141(199903)29:03<1004::AIDIMMU1004>3.0.CO;2-Q)

Harvey MB \& Kaye PL 1992a IGF-2 stimulates growth and metabolism of early mouse embryos. Mechanisms of Development 38 169-173. (doi:10.1016/0925-4773(92)90050-T)

Harvey MB \& Kaye PL 1992b Mediation of the actions of insulin and insulin-like growth factor-1 on preimplantation mouse embryos in vitro. Molecular Reproduction and Development 33 270-275. (doi:10.1002/ mrd.1080330306)

Harvey MB, Leco KJ, Arcellana-Panlilio MY, Zhang X, Edwards DR \& Schultz GA 1995 Proteinase expression in early mouse embryos is regulated by leukaemia inhibitory factor and epidermal growth factor. Development 121 1005-1014.

Hedborg F, Holmgren L, Sandstedt B \& Ohlsson R 1994 The cell typespecific IGF2 expression during early human development correlates to the pattern of overgrowth and neoplasia in the Beckwith-Wiedemann syndrome. American Journal of Pathology 145 802-817.

Hegde A \& Behr B 2012 Media composition: growth factors. Methods in Molecular Biology 912 177-198. (doi:10.1007/978-1-61779-971-6_11)

Ho Sui SJ, Mortimer JR, Arenillas DJ, Brumm J, Walsh CJ, Kennedy BP \& Wasserman WW 2005 oPOSSUM: identification of over-represented 
transcription factor binding sites in co-expressed genes. Nucleic Acids Research 33 3154-3164. (doi:10.1093/nar/gki624)

Houghton FD, Hawkhead JA, Humpherson PG, Hogg JE, Balen AH, Rutherford AJ \& Leese HJ 2002 Non-invasive amino acid turnover predicts human embryo developmental capacity. Human Reproduction 17 999-1005. (doi:10.1093/humrep/17.4.999)

Huang DW, Sherman BT, Tan Q, Kir J, Liu D, Bryant D, Guo Y, Stephens R, Baseler MW, Lane HC et al. 2007 DAVID Bioinformatics Resources: expanded annotation database and novel algorithms to better extract biology from large gene lists. Nucleic Acids Research 35 W169-W175. (doi:10.1093/nar/gkm415)

Jahangiri M, Shahhoseini M \& Movaghar B 2014 H19 and MEST gene expression and histone modification in blastocysts cultured from vitrified and fresh two-cell mouse embryos. Reproductive BioMedicine Online 29 559-566. (doi:10.1016/j.rbmo.2014.07.006)

Jiang Q, Chen S \& Xing F 2000 Expression of epidermal growth factor receptor in human preimplantation embroys. Zhonghua Fu Chan Ke Za Zhi 35 468-469.

Jin XL \& O'Neill C 2014 Systematic analysis of the factors that adversely affect the rate of cell accumulation in mouse embryos during their culture in vitro. Reproductive Biology and Endocrinology 1235. (doi:10.1186/1477-7827-12-35)

Kjoller L, Kanse SM, Kirkegaard T, Rodenburg KW, Ronne E, Goodman SL, Preissner KT, Ossowski L \& Andreasen PA 1997 Plasminogen activator inhibitor-1 represses integrin- and vitronectin-mediated cell migration independently of its function as an inhibitor of plasminogen activation. Experimental Cell Research 232 420-429. (doi:10.1006/ excr.1997.3540)

Kreiling JL, Byrd JC, Deisz RJ, Mizukami IF, Todd RF 3rd \& MacDonald RG 2003 Binding of urokinase-type plasminogen activator receptor (uPAR) to the mannose 6-phosphate/insulin-like growth factor II receptor: contrasting interactions of full-length and soluble forms of uPAR. Journal of Biological Chemistry 278 20628-20637. (doi:10.1074/jbc. M302249200)

Kubo H, Spindle A \& Pedersen RA 1981 Inhibition of mouse blastocyst attachment and outgrowth by protease inhibitors. Journal of Experimental Zoology 216 445-451. (doi:10.1002/jez.1402160313)

Kurzawa R, Glabowski W \& Wenda-Rozewicka L 2001 Evaluation of mouse preimplantation embryos cultured in media enriched with insulin-like growth factors I and II, epidermal growth factor and tumor necrosis factor alpha. Folia Histochemica et Cytobiologica 39 245-251.

Lefebvre L, Viville S, Barton SC, Ishino F, Keverne EB \& Surani MA 1998 Abnormal maternal behaviour and growth retardation associated with loss of the imprinted gene Mest. Nature Genetis 20 163-169. (doi:10.1038/2464)

Lighten AD, Hardy K, Winston RM \& Moore GE 1997 Expression of mRNA for the insulin-like growth factors and their receptors in human preimplantation embryos. Molecular Reproduction and Development 47 134-139. (doi:10.1002/(SICl)1098-2795(199706)47:2<134::AIDMRD2>3.0.(O;2-N)

Lin TC, Yen JM, Gong KB, Hsu TT \& Chen LR 2003 IGF-1/IGFBP-1 increases blastocyst formation and total blastocyst cell number in mouse embryo culture and facilitates the establishment of a stem-cell line. BMC Cell Biology 4 14. (doi:10.1186/1471-2121-4-14)

Liu Z, Brattain MG \& Appert H 1997 Differential display of reticulocalbin in the highly invasive cell line, MDA-MB-435, versus the poorly invasive cell line, MCF-7. Biochemical and Biophysical Research Communications 231 283-289. (doi:10.1006/bbrc.1997.6083)

Mayer W, Hemberger M, Frank HG, Grummer R, Winterhager E, Kaufmann P \& Fundele R 2000 Expression of the imprinted genes MEST/ Mest in human and murine placenta suggests a role in angiogenesis. Developmental Dynamics 217 1-10. (doi:10.1002/(SICl)10970177(200001)217:1<1::AID-DVDY1>3.0.CO;2-4)

Menino AR Jr \& O'Claray JL 1986 Enhancement of hatching and trophoblastic outgrowth by mouse embryos cultured in Whitten's medium containing plasmin and plasminogen. Journal of Reproduction and Fertility 77 159-167. (doi:10.1530/jrf.0.0770159)

Menino AR Jr, Dyk AR, Gardiner CS, Grobner MA, Kaaekuahiwi MA \& Williams JS 1989 The effects of plasminogen on in vitro ovine embryo development. Biology of Reproduction 41 899-905. (doi:10.1095/ biolreprod41.5.899)
Mi H, Muruganujan A \& Thomas PD 2013 PANTHER in 2013: modeling the evolution of gene function, and other gene attributes, in the context of phylogenetic trees. Nucleic Acids Research 41 D377-D386. (doi:10.1093/nar/gks1118)

Nelissen EC, Van Montfoort AP, Coonen E, Derhaag JG, Geraedts JP, Smits LJ, Land JA, Evers JL \& Dumoulin JC 2012 Further evidence that culture media affect perinatal outcome: findings after transfer of fresh and cryopreserved embryos. Human Reproduction 27 1966-1976. (doi:10.1093/humrep/des145)

Nykjaer A, Christensen El, Vorum H, Hager H, Petersen CM, Roigaard H, Min HY, Vilhardt F, Moller LB, Kornfeld S et al. 1998 Mannose 6-phosphate/insulin-like growth factor-II receptor targets the urokinase receptor to lysosomes via a novel binding interaction. Journal of Cell Biology 141 815-828. (doi:10.1083/jcb.141.3.815)

O'Neill C 1997 Evidence for the requirement of autocrine growth factors for development of mouse preimplantation embryos in vitro. Biology of Reproduction 56 229-237. (doi:10.1095/biolreprod56.1.229)

Olson LJ, Yammani RD, Dahms NM \& Kim JJ 2004 Structure of UPAR, plasminogen, and sugar-binding sites of the $300 \mathrm{kDa}$ mannose 6-phosphate receptor. EMBO Journal 23 2019-2028. (doi:10.1038/ sj.emboj.7600215)

Pantaleon M, Jericho H, Rabnott G \& Kaye PL 2003 The role of insulin-like growth factor II and its receptor in mouse preimplantation development. Reproduction, Fertility and Development 15 37-45. (doi:10.1071/ RD02031)

Rappolee DA, Sturm KS, Behrendtsen O, Schultz GA, Pedersen RA \& Werb Z 1992 Insulin-like growth factor II acts through an endogenous growth pathway regulated by imprinting in early mouse embryos. Genes and Development 6 939-952. (doi:10.1101/gad.6.6.939)

Reed ML, Woodward BJ \& Swain JE 2011 Single or group culture of mammalian embryos: the verdict of the literature. Journal of Reproductive and Stem Cell Biotechnology 2 77-87. (doi:10.1177/20589158110020 0203)

Richter KS 2008 The importance of growth factors for preimplantation embryo development and in-vitro culture. Current Opinion in Obstetrics and Gynecology 20 292-304. (doi:10.1097/ GCO.0b013e3282fe743b)

Roberts CT, Sferruzzi-Perri AN, Owens JA \& Ng P 2007 Distinct effects of insulin-like growth factors (IGF) on placental invasion and function. Placenta 28 A5; P13.

Sappino AP, Huarte J, Belin D \& Vassalli JD 1989 Plasminogen activators in tissue remodeling and invasion: $\mathrm{mRNA}$ localization in mouse ovaries and implanting embryos. Journal of Cell Biology 109 2471-2479. (doi:10.1083/jcb.109.5.2471)

Sara VR \& Hall K 1990 Insulin-like growth factors and their binding proteins. Physiological Reviews 70 591-614.

Schultz GA, Hogan A, Watson AJ, Smith RM \& Heyner S 1992 Insulin, insulin-like growth factors and glucose transporters: temporal patterns of gene expression in early murine and bovine embryos. Reproduction, Fertility and Development 4 361-371. (doi:10.1071/RD9920361)

Schultz GA, Hahnel A, Arcellana-Panlilio M, Wang L, Goubau S, Watson A \& Harvey M 1993 Expression of IGF ligand and receptor genes during preimplantation mammalian development. Molecular Reproduction and Development 35 414-420. (doi:10.1002/ mrd.1080350416)

Sjoblom C, Wikland M \& Robertson SA 2002 Granulocyte-macrophage colony-stimulating factor (GM-CSF) acts independently of the beta common subunit of the GM-CSF receptor to prevent inner cell mass apoptosis in human embryos. Biology of Reproduction 67 1817-1823. (doi:10.1095/biolreprod.101.001503)

Stojanov T, Alechna S \& O'Neill C 1999 In-vitro fertilization and culture of mouse embryos in vitro significantly retards the onset of insulin-like growth factor-II expression from the zygotic genome. Molecular Human Reproduction 5 116-124. (doi:10.1093/molehr/5.2.116)

Sturmey RG, Brison DR \& Leese HJ 2008 Symposium: innovative techniques in human embryo viability assessment. Assessing embryo viability by measurement of amino acid turnover. Reproductive BioMedicine Online 17 486-496.

Teesalu T, Blasi F \& Talarico D 1996 Embryo implantation in mouse: fetomaternal coordination in the pattern of expression of UPA, UPAR, PAI-1 and alpha 2MR/LRP genes. Mechanisms of Development $\mathbf{5 6}$ 103-116. (doi:10.1016/0925-4773(96)00515-1) 
Van Winkle LJ 2001 Amino acid transport regulation and early embryo development. Biology of Reproduction 64 1-12. (doi:10.1095/ biolreprod64.1.1)

Wanggren K, Lalitkumar PG, Hambiliki F, Stabi B, Gemzell-Danielsson K \& Stavreus-Evers A 2007 Leukaemia inhibitory factor receptor and gp130 in the human Fallopian tube and endometrium before and after mifepristone treatment and in the human preimplantation embryo. Molecular Human Reproduction 13 391-397. (doi:10.1093/molehr/gam013)

Worrad DM \& Schultz RM 1997 Regulation of gene expression in the preimplantation mouse embryo: temporal and spatial patterns of expression of the transcription factor Sp1. Molecular Reproduction and Development $46 \quad 268-277 . \quad$ (doi:10.1002/(SICI)10982795(199703)46:3<268::AID-MRD5>3.0.CO;2-N)
Zhang X, Kidder GM, Zhang C, Khamsi F \& Armstrong DT 1994 Expression of plasminogen activator genes and enzymatic activities in rat preimplantation embryos. Journal of Reproduction and Fertility 101 235-240. (doi:10.1530/jrf.0.1010235)

Received 19 September 2016

First decision 20 October 2016

Revised manuscript received 30 November 2016

Accepted 19 December 2016 